\title{
Economia Solidária e Design Social: iniciativas sustentáveis com resíduos vegetais para produção artesanal
}

\author{
Solidarity Economy, Social Technology and Design: sustainable initiatives with \\ residue Cerrado for handicraft production in extractive communities

\section{Economie Solidaire, Technologie Sociale et Design: des initiatives durables avec résidu Cerrado pour la production de l'artisanat dans les communautés extractives}

Economía Solidaria, Tecnología Social y Design: iniciativas sostenibles con residuos Cerrado para la producción de artesanías en las comunidades extractivas

\author{
Nadja Maria Mourão* \\ (nadjamourao@gmail.com) \\ Rita de Castro Engler* \\ (rcengler@ryerson.ca)
}

Recebido em 10/12/2013; revisado e aprovado em 15/02/2014; aceito em 25/02/2014

\begin{abstract}
Resumo: Este estudo busca conhecer os fundamentos da Economia Solidária visando possibilitar a atuação do Design Social, como alternativa para o desenvolvimento econômico, de forma sustentável. As comunidades de "Bonfinópolis de Minas" e "Chapada Gaúcha", Minas Gerais, Brasil desenvolvem o extrativismo de frutos do Cerrado, através de associações e cooperativas. Nessas comunidades são verificadas as possibilidades de uso dos resíduos vegetais em produção artesanal como alternativa empreendedora local.

Palavras-chave: Economia Solidária. Tecnologia Social. Design Social.
\end{abstract}

Abstract: This study seeks to understand the foundations of Solidarity Economy aiming to make possible the work of the Social Design as an alternative to economic development in a sustainable manner. Communities "Bonfinópolis de Minas" and "Chapada Gaúcha", Minas Gerais, Brazil develop the extraction of Cerrado fruits, through associations and cooperatives. In these communities the possibilities of use of vegetable waste in craft production as a local entrepreneurial alternative are checked.

Key words: Solidarity Economy. Social Technology. Social Design.

Résumé: Cette étude cherche à comprendre les fondements de l’Économie Solidaire visant à rendre possible la performance du Design Social comme une alternative au développement économique durable. Les communautés "Bonfinópolis de Minas" et "Chapada Gaúcha”, Minas Gerais, Brésil développent l'extraction des fruits du Cerrado, à travers des associations et des coopératives. Dans ces communautés, les possibilités d'utilisation de débris végétaux dans la production artisanale comme une alternative entrepreneuriale locale sont vérifiés.

Mots-clés: Économie Solidaire. Technologie Sociale. Design Sociale.

Resumen: Este estudio trata de comprender los fundamentos de la Economía Solidaria con el objetivo de hacer posible la realización de la Diseño Social como alternativa para el desarrollo económico de una manera sostenible. Comunidades “Bonfinópolis de Minas" y “Chapada Gaúcha”, Minas Gerais, Brasil a desarrollar la extracción de las frutas del Cerrado, a través de asociaciones y cooperativas. En estas comunidades se comprueban las posibilidades de uso de los restos vegetales en producción artesanal como una alternativa empresarial local.

Palabras clave: Economía Solidaria. Tecnología Social. Diseño Social.

\section{Introdução}

Em razão das recentes crises econômicas nas últimas décadas, indivíduos se agrupam em busca de soluções e novas possibilidades. É na motivação dos trabalhadores que surgem organizações e grupos solidários de autogestão. Esses empreendimentos são sustentados pela força no potencial no trabalho coletivo que os compõe, impulsionando uma fonte de competitividade reconhecida no capitalismo.
No Brasil, o crescimento da Economia Solidária deve-se a fatores diversificados. Os problemas de moradia dos trabalhadores, pela crescente exclusão, desocupação rural e desemprego urbano é resultado da expansão agressiva dos impactos negativos do capitalismo e da globalização. A resistência dos trabalhadores rurais em permanecerem em suas terras ocorre, acima de tudo, como batalha por melhores condições de vida. Buscam adaptação através de um mercado informal crescente, no qual germinam as iniciativas de economia popular.

\footnotetext{
* Centro de Estudos em Design e Tecnologia da Escola de Design (CEDTec/UEMG), Barbacena, MG, Brasil.
} 
No meio rural, o sistema agroextrativista, o trabalho compartilhado em cestarias e rendas artesanais, a produção e comercialização de biscoitos e doces entre outros, normalmente de caráter individual ou familiar, são exemplos dos modelos da Economia Solidária.

De acordo com Gaiger (2004), "uma experiência profissional é fundamentada na equidade e na dignidade, na qual ocorre um enriquecimento do ponto de vista cognitivo e humano". Quanto maior a participação, maior a motivação do empregado, que, nesse caso, é também responsável pelo sucesso do empreendimento.

A Economia Solidária representa instrumento de combate à exclusão social na medida em que apresenta alternativa viável para a geração de trabalho e renda e para a satisfação direta das necessidades humanas, eliminando as desigualdades materiais e difundindo os valores da ética e da solidariedade, conforme Nascimento (2006).

Acredita-se que o design social pode contribuir com novos métodos que incentivem o desenvolvimento em comunidades. Para que o trabalho do design seja efetivo e proveitoso nesses empreendimentos sociais, é necessária uma abordagem sistêmica demonstrando que formas de organização social que valorizam iniciativas criativas encontramse cada vez mais emergentes, dentro de uma demanda social que procura por um desenvolvimento de vida sustentável.

Este trabalho busca analisar o uso de resíduos vegetais em produção artesanal sustentável, como alternativa para desenvolver o empreendedorismo em comunidades rurais extrativistas do cerrado mineiro. Oficinas de Design, identidade e cultura foram aplicadas nas comunidades de Bonfinópolis de Minas e Chapada Gaúcha.

A investigação inicial contou com apoio do Centro de Tecnologia de Minas Gerais CETEC/ Projeto de Implantação de Unidades de Beneficiamento e Comércio de Produtos Oriundos da Base Produtiva Local e com recursos do Instituto Sociedade, População e Natureza - ISPN / Projeto Florelos / Edital Unicom 2010. Âs instituições parceiras, registram-se agradecimentos. Em seguida, nova etapa da pesquisa configurou-se na produção da dissertação: "Sustentabilidade na produção artesanal com resíduos vegetais: uma aplicação prática de design sistêmico no cerrado mineiro", reconhecida em 2012, como exemplo de incentivo à Economia Criativa, em Arranjos Produtivos Locais.

\section{Revisão da literatura}

\section{Conceitos da Economia Solidária}

Economia Solidária é um modelo de organizar a produção, a distribuição e o consumo, estruturado sob a igualdade de direitos e responsabilidades de todos. Entre suas características destacam a autogestão, a autonomia de cada unidade ou empreendimento e a igualdade entre os participantes ou membros, conforme Singer (2002).

A origem de economia contribui para a compreensão dessa postura. O termo economia vem do grego oikos (casa) e nomos (costume ou lei) ou também gerir, administrar: daí "regras da casa" e "administração da casa". Assim, o termo "economia configura-se como a ciência social que estuda a produção, distribuição e consumo de bens e serviços" (FERREIRA, 1999, p. 617).

Os elementos de produção ou serviços, fundamentados no cooperativismo, são gerenciados pela propriedade coletiva, buscando sempre um método próprio de gestão. Lima (2011) relata que esses elementos estabelecem limites entre a produção, consumo e comercialização, buscando a qualidade de vida. Interpretam o trabalho como um meio de libertação do ser humano na democratização econômica, recriando alternativas assalariadas nas relações do capitalismo.

Entre os conceitos de Economia Solidária, registram as investigações de Paul Singer ${ }^{1}$, que a considera como uma estratégia possível para diminuir as desigualdades sociais e o desemprego. "Tudo leva a acreditar que a Economia Solidária permitirá, ao cabo de alguns anos, dar a muitos, que esperam em vão um novo emprego, a oportunidade de se reintegrar à produção por conta própria individual ou coletivamente" (SINGER, 2000, p. 138).

\footnotetext{
${ }^{1}$ Sociólogo, pesquisador, professor da USP e primeiro secretário nacional de Economia Solidária do Ministério do Trabalho e Emprego, criada em 2003.
} 
Euclides André Mance, filósofo, membro de movimentos sociais como a Central de Movimentos Populares do Brasil, garante que o conceito vai além e agrega valores não apenas de geração de postos de trabalho, mas como contribuição solidária para mudança de comportamento:

Ao considerarmos a colaboração solidária como um trabalho e consumo compartilhados cujo vínculo recíproco entre as pessoas advém, primeiramente, de um sentido moral de corresponsabilidade pelo bemviver de todos e de cada um em particular, buscando ampliar-se o máximo possível o exercício concreto da liberdade pessoal e pública, introduzimos no cerne desta definição o exercício humano da liberdade. (MANCE, 1999, p. 178).

A Economia Solidária procura diminuir fronteiras, sejam elas barreiras nacionais, sociais, culturais, raciais, religiosas e até mesmo as acadêmicas. Assim reafirma a importância de representantes da própria comunidade, ou seja, a emancipação de trabalhadores como indivíduos históricos de um olhar inovador para novas perspectivas nas relações comerciais.

A empresa solidária visa a um ponto comum a todose, quando bem estruturada pelos trabalhadores, que também são proprietários, encontra os meios para seus objetivos. Sua meta não é fundamentalmente de elevar ao máximo os lucros e rendimentos, mas como ele é distribuído e, acima de tudo, a qualidade do trabalho. A divisão dos benefícios, definida por todos os associados, busca garantir o sucesso do empreendimento, estimular maior comprometimento com o refinamento do processo produtivo, o cuidado para não ocorrer desperdícios, além de inibir a negligência, conforme Singer (2002).

\section{Raízes da Economia Solidária}

Práticas econômicas, originadas pelos princípios de solidariedade, sempre existiram em diversas partes do mundo, antes da Revolução Industrial. As práticas solidárias estão presentes nas tradições asiáticas, africanas, pré-colombianas e europeias, conforme Lima (2011).

O modelo do capitalismo, consolidado durante a Revolução Industrial, promoveu o domínio do conhecimento e da tecnologia.
Piana (2009) relata que esses fatores aliados a um capital inicial fortalecido transformaram os empregados em subordinados aos objetivos do empregador, muito semelhante ao sistema de escravidão. Esse modelo econômico provocou a reação dos artesãos expulsos dos mercados pelo advento da máquina a vapor, consolidando assim novas formas econômicas em contraposição ao modelo vigente.

A estrutura da Economia Solidária foi estabelecida na passagem do século XVIII para XIX, quando surgiram, na Grã-Bretanha, as primeiras Uniões de Ofícios e as primeiras Cooperativas. Para Gaiger (2004), a Cooperativa de Consumo dos Pioneiros Equitativos de Rochdale (1844) iniciou um processo que estendeu para grandes empreendimentos, expandindo-se na Europa e demais economias do mundo.

Nos primórdios dos processos industriais, certa alienação era atestada, em que a linha de produção distanciava o ser humano da compreensão do produto fabricado. "Enquanto no fordismo a competitividade é obtida através das economias de escala e de uma crescente divisão e alienação do trabalho associadas a linhas produtivas rígidas - automatizadas ou não, na nova base técnica que está se configurando, uma importante fonte de eficiência é a flexibilização" (GAIGER, 2004, p. 64).

Comparando ao modelo capitalista, conforme Singer (2002), o principal elemento que distancia a Economia Solidária deste é a desigualdade. O capitalismo desequilibrado perde o valor das qualificações e, muitas vezes, bons profissionais se tornam miseráveis. Quando a cooperação comanda as relações, cria-se um ambiente tolerante, possibilitando o processo de recuperação da economia desestruturada. Assim, a Economia Solidária é um modelo que se adapta às comunidades com situações enfraquecidas, principalmente após grandes calamidades e perdas socioambientais.

Na França, após as revoluções de 1848, surgem cooperativas de produção a partir de empreendimentos capitalistas abandonados pelos empregadores, conforme Souza (1992). Na Prússia, depois de 1850, são criadas as primeiras cooperativas de crédito urbanas, junto com as experiências dos pioneiros de Rochdale na Grã-Bretanha. A busca para manter grupos sociais possibilitou a mudança de sistemas na Europa em declínio. 
Souza (1992) ainda esclarece que esses novos modelos de cooperativismo também contribuíram para a formação do moderno pensamento participativo. Entretanto, devido às particularidades regionais, especialmente na Alemanha e na Itália, seus princípios se diferenciaram dos pioneiros de Rochdale. São diferentes os subtipos específicos incorporados aos novos modelos de cooperativas. "Dentro desse quadro histórico, inicia-se a implantação de sociedades cooperativas. Seu crescimento será dificultado no início do século XX, pela I Guerra Mundial" (SOUZA, 1992, p. 107). Somente no final da II Guerra, o movimento expande, consolidando-o na década de sessenta.

Após os anos 80, com a eliminação de grande número de trabalhadores do mercado, o modelo de trabalho associativo e cooperativo retorna ao quadro mundial, Lima (2011). Porém não apresenta as mesmas características anteriores, surge um modelo cooperativo mais próximo de suas origens. Outras formas institucionais de autogestão são inventadas e passam a ser conhecidas como a Economia Solidária.

Das origens até hoje, a Economia Solidária é apresentada como um processo de aproximação do trabalhador com seus meios de produção. O trabalhador passa a conhecer um pouco mais das atividades que ele e os demais executam, renovando o foco das críticas. Fora da administração participativa, o empregado pouco contribui para o desenvolvimento dos produtos, pois critica somente o que não compreende.

\section{Economia Solidária no Brasil}

No Brasil, durante a última década, a crescente organização da Economia Solidária enquanto um movimento - ou seja, ultrapassando a dimensão de iniciativas isoladas e fragmentadas no que diz respeito à sua inserção nas cadeias produtivas e nas articulações do seu entorno -, é orientada para articulação nacional, com a configuração de redes locais e o estabelecimento de uma plataforma comum, conforme Soares (2009).

Gaiger (2004) relata que as manifestações da Economia Solidária são bastante diversificadas no território brasileiro: cooperativas, associações populares e grupos informais (de produção, de serviços, de consumo, de comercialização e de crédito solidário, nos âmbitos rural ou urbano); empresas recuperadas de autogestão (antigas empresas capitalistas falidas recuperadas pelos trabalhadores); agricultores familiares; fundos solidários e rotativos de crédito (organizados sob diversas formas jurídicas e também informalmente); clubes e grupos de trocas solidárias (com ou sem o uso de moeda social, ou moeda comunitária); ecovilas; redes e articulações de comercialização e de cadeias produtivas solidárias; lojas de comércio justo; agências de turismo solidário, entre outras.

Em regiões onde o coronelismo foi historicamente privilegiado no Brasil, existem ainda grupos sociais com perfil submisso pelos grupos dominantes locais. Os objetivos da Economia Solidária são fundamentados na transformação do sistema atual de concorrência e ação pela sobrevivência e pelo controle do poder. Busca despertar a consciência das relações familiares no que tange à dimensão social, econômica, administrativa, educacional, política, jurídica, ecológica e cultural existente.

Segundo Santos (2000), a insistência na viabilidade das alternativas não implica uma aceitação da realidade. "A afirmação fundamental do pensamento crítico consiste na asserção de que a realidade não se reduz ao que existe. A realidade é um campo de possibilidades em que têm cabimento as alternativas que foram marginalizadas ou que nem sequer foram tentadas" (SANTOS, 2000, p. 23).

Conforme Dagnino (2009), a decisão de transformar a dinâmica da exclusão da economia informal na de inclusão, via geração de oportunidades de trabalho e renda da Economia Solidária e a manutenção das políticas sociais compensatórias, torna indispensável e oportuno o desenvolvimento também das tecnologias sociais e outras adequações.

\section{Design Social}

A palavra Design, usada em todos os meios de comunicação expressando atributos de qualidade e funcionalidade, torna-se cada vez mais popular. Os conceitos do design surgem associados aos valores globalizados de propriedade e estética, qualificando-o como 
processo criativo, inovador e provedor de soluções. Por envolver aspectos que visam ao ser humano ético, social, cultural e ambiental, os valores fundamentais e transversais do design ultrapassam as esferas produtivas, tecnológicas e econômicas.

O design social, com aplicabilidade na sociedade com objetivo de melhorar a qualidade de vida, pode se definido como um método de planejamento de produtos ou serviços. Papanek (1984) defende o conceito de que os designers e profissionais de criação podem causar mudanças positivas para a sociedade através de um bom projeto de design. O design aplicado com responsabilidade ambiental, social e econômica. O designer responsável deve saber como projetar, qual material utilizar e como atender à demanda.

O design agrega-se ao desenvolvimento de produtos e serviços, em áreas diversificadas que vão de agricultura à industrialização, com a função de atender às necessidades sociais. Penin (2006) elucida que o "Sistema Produto-Serviço" é resultado de uma atividade estratégica do design, entendida como a capacidade de promover novas formas de organização. Essas inovações em organizações estão estruturadas sob um novo sistema de valores e na aptidão para criar novas oportunidades. Podem desenvolver um sistema integrado de produtos e serviços economicamente viáveis e adequado à sociedade.

Compreender e utilizar processos de projeto sociais pode contribuir para a melhoria dos meios de subsistência. Sen (2000) sugere que o desenvolvimento dentro de vários aspectos sociais pode contribuir para o desenvolvimento geral. Ele relata que a pobreza é vista como privação de competências, e estas devem ser estimuladas para resolver os problemas sociais.

O Design social pode ser considerado como um processo que leva a capacidades humanas, que por sua vez contribui para o seu bem-estar. Sendo assim, "é necessário adotar outros fatores imponderáveis, qualitativos e não quantitativos de valor e do ambiente, o grau de instrução e os serviços, isto é, os índices que manifestam o grau de bem-estar não material, mas moral das pessoas" (BISTAGNINO, 2009, p. 15).

\section{Design e Economia Solidária}

As relações do Design com a Economia Solidária surgiram no início da sistematização das categorias ou grupos de produção. Desde sua origem, conforme Manzini e Vezzoli (2002), o design perpassa pelas manufaturas e contribui para que os processos artesanais culminem em linhas de produção. Essas relações ainda não eram denominadas como Design e Economia Solidária, mas como manufaturas familiares que contribuíram para o desenvolvimento de localidades.

O Design, qualificado como instrumento para alcançar a inovação através de vantagens competitivas, direciona-se para outros aspectos do desenvolvimento de produtos e serviços. Conforme Engler (2009), inovação é uma característica do design concebida através do planejamento, da estratégia, do marketing, da qualidade e da forma de produção. Esses procedimentos reorganizam as relações com os resultados alcançados. Contudo o objetivo principal dessa profissão é servir ao ser humano, seja nas relações entre os serviços, produtos ou ambos simultaneamente.

Mudanças de padrões motivados pela recombinação de elementos efetuam o conceito de inovação social, estabelecendo elos entre a sociedade, territoriedade e comunicação. Para tanto, considera-se o consumo como fator de manutenção do ser humano em qualquer dimensão. Mas consumir com equilíbrio consiste nas limitações das necessidades. O bem estar, no entanto, vincula-se ao grau de conhecimento da pessoa, ponderando escolhas relacionadas à qualidade de vida, conforme Hall (2005).

Contextualiza-se inovação como principal fator de competitividade, mola mestra entre as relações com indivíduos, associações, organizações empresariais e até mesmo países e blocos econômicos. Engler (2009) esclarece que essa característica deve manter-se constante. Ocorre por meio da sistematização de iniciativas, visando à vinculação entre estratégias de negócio e oportunidades explícitas, principalmente no âmbito empresarial. Estão estruturadas sob o foco da implementação de novos ou diferentes processos, serviços ou produtos.

Se desejarmos melhorar e crescer, precisamos inovar. Não é possível esperar 
resultados diferentes fazendo sempre a mesma coisa. Portanto, as organizações que desejam estar em constante crescimento precisam se reinventar constantemente. A inovação faz parte da rotina e deve ser tarefa de todos. (ENGLER, 2009, p. 66).

O Design percorre a evolução dos materiais e processos, transitando por todas as fases de um serviço ou produto, seja este artesanal ou não. Assim, design e economia solidária buscam por soluções sustentáveis, em novos métodos de organização e produção, de grupos comunitários, associações e cooperativas; apresentar-se em perspectivas de soluções e novos caminhos para a sociedade no caótico mundo capitalista gerado pelo ser humano. Os avanços entre a tecnologia, a inovação e o design podem alcançar dimensões que lidam com as diferenças, conflitos históricos sociais até os problemas mais comuns dos produtos locais.

\section{As comunidades extrativistas do Cerrado Mineiro - Vale do Urucuia}

Nas regiões de cerrado, o uso sustentável da biodiversidade é realidade para comunidades. Os recursos naturais servem como geração de renda, segurança alimentar e qualidade de vida para a população local. Os povos tradicionais, sertanejos e ribeirinhos utilizam-se de plantas, raízes e frutos, como alimento, medicamento e fonte de renda. Para algumas comunidades, além da necessidade de manutenção, o cerrado representa sua herança cultural.

Barbosa (2008) relata que, de todos os sistemas biogeográficos da América do Sul, o Cerrado é o que fornece maior variedade de frutos comestíveis, para seus habitantes. E, embora a maturação da maior parte esteja relacionada à estação de chuvas, a grande variedade possibilita a distribuição equilibrada de muitas espécies o ano todo.

De acordo com os dados do Instituto Brasileiro do Meio Ambiente e dos Recursos Naturais Renováveis (IBAMA, 2003), o cerrado brasileiro é reconhecido como a savana mais rica do mundo em biodiversidade, com a presença de diversos ecossistemas. Parte-se do pressuposto de que a grande biodiversidade vegetal desse bioma possa fornecer resíduos vegetais viáveis ao uso no artesanato, e sem comprometer a integridade ecológica desse ecossistema. Sementes de frutos, cascas, folhas, galhos, etc., podem ser matéria prima no aproveitamento em objetos decorativos, adornos e utilitários.

No Noroeste de Minas, incluindo a bacia do Rio Urucuia, o clima é quente. A temperatura média é superior a $18^{\circ} \mathrm{C}$, durante todo o ano. $\mathrm{O}$ inverno é ameno e o verão é sempre quente e muito longo (setembro a março). Na bacia hidrográfica do Rio Urucuia, estão vários municípios, entre eles: Bonfinópolis de Minas e Chapada Gaúcha.

Esses municípios localizam-se entre o Rio São Francisco e o Parque Nacional Grande Sertão Veredas. O Instituto Estadual de Florestas (IEF) constata que essa região possui características naturais únicas, que apresentam um grande potencial turístico e que justificaram sua conservação dentro de três Unidades de Conservação.

Nas comunidades rurais dessa região, pratica-se o extrativismo de soja, milho e dos frutos do cerrado, especialmente buriti, jatobá e a fava d'anta - Dimorphandra mollis Benth (beneficiada para retirada da rutina, substância utilizada para medicamentos e comercializada para laboratórios), conforme Madeira e Cèzar (2009).

\section{Metodologia}

A metodologia deste trabalho consiste inicialmente na revisão, contextualização e análise do referencial teórico, que possibilita análise científica dos dados, em todo o processo de investigação. Assim, permanece a busca pela eficácia dos dados registrados e outros que possam contribuir com os objetivos, nas temáticas de: economia solidária, design social, comunidades extrativistas, resíduos vegetais e produção artesanal.

Em seguida, a investigação foi conduzida por uma metodologia de natureza qualitativa com formato de estudo de caso, fundamentado em considerações metodológicas apresentadas por Lüdcke e André (1986). Para os autores, a observação permite que o observador se aproxime das pessoas, acompanhando "in loco as experiências diárias dos sujeitos, pode apreender a sua visão do mundo, isto é, o significado que eles atribuem à realidade que os cerca e às suas próprias acções" (LÜDCKE; ANDRÉ, 1986, p. 26). 
No sentido de delimitar a análise, além do recorte no território mineiro, realizou-se um estudo específico para as comunidades extrativistas do Vale do Urucuia, municípios de Bonfinópolis de Minas e Chapada Gaúcha. Essa região caracteriza-se pela carência de investimentos sociais e pela dificuldade de acesso, devido aos aspectos geográficos (sertões, veredas e chapadões).

O levantamento socioambiental cultural das comunidades permitiu a identificação de ícones da cultura local, manifestações e recursos oriundos da região, poucos explorados pela população, tendo sua produção e comercialização comprometida. Realizou-se um levantamento dos valores culturais que possibilitem a utilização de metodologias de design para seu desenvolvimento.

A existência de grupos solidários, associações e cooperativas locais, facilitou o levantamento de dados socioambientais e culturais da região. Foi documentada a percepção e sensibilização ambiental, que ajudaram os produtores a conhecer melhor o meio ambiente no qual estão inseridos. Registraram-se outras espécies florísticas que podem ser utilizadas no projeto. Definiram-se os materiais para produção artesanal, considerando os resíduos vegetais como recursos e insumos.

Os resíduos naturais, descritos por Mourão (2011), são partes e produtos das plantas que naturalmente são lançadas no meio ambiente com a possibilidade de serem reutilizadas, evitando-se comprometer a permanência das espécies vegetais nativas da região. Assim, consideram-se reutilizáveis as partes secas de flores, folhas e galhos, sementes não germinativas, etc.

Evidenciou-se a necessidade de se propor o desenvolvimento de uma ação sistêmica para resgatar o artesanato local e sua identidade, visto que este se encontrava desvalorizado por fatores socioeconômicos influenciados pela globalização, desconectado da realidade da comunidade local tão rica em expressões e elementos culturais regionais.

Assim, a estratégia adotada consistiu em propor o desenvolvimento de novos produtos artesanais tendo como base o Artesanato de Referência Cultural². Várias atividades

\footnotetext{
2 Artesanato de Referência Cultural é um produto cuja característica é a incorporação de elementos culturais
}

ocorrem simultaneamente, como a elaboração de oficinas de design para a comunidade, facilitando o desenvolvimento do cronograma nas etapas da pesquisa: revisão da bibliografia, diagnóstico socioambiental e cultural das comunidades, desenvolvimento de oficinas de design e proposta de produção artesanal.

\section{Desenvolvimento das oficinas para produção artesanal}

Foram definidas as comunidades de Cana Brava e São Pedro (Bonfinópolis de Minas) e Serra das Araras (Chapada Gaúcha) durante o desenvolvimento dos cursos de "Capacitação em Beneficiamento e Produção com Frutos do Cerrado" e "Aproveitamento dos Resíduos Vegetais do Cerrado Mineiro para o Artesanato". Esses cursos são destinados aos cooperados e grupos de produção com insumos do Cerrado, principalmente nas comunidades acordadas pelo Projeto de Implantação de Unidades de Beneficiamento e Comércio de Produtos Oriundos da Base Produtiva Local. CETEC/MG - Convênio n. 411/2007 (MADEIRA, 2008), celebrado entre o MDS, a Prefeitura de Bonfinópolis de Minas/Chapada Gaúcha e o CONSAD Urucuia Grande Sertão Veredas - Programa Fome Zero. A parceria da pesquisa com outros projetos viabiliza o levantamento de dados e deslocamento local com domínio e flexibilidade.

As capacitações, ofertadas para as comunidades pelo projeto citado anteriormente, englobam conteúdos de educação ambiental, manejo de plantas, de nutrição, boas práticas de produção, processamento, certificação, embalagem e comercialização solidária de base regional. Os cursos para implantação de unidades de manejo e beneficiamento enfatizaram em aulas práticas, como coletar os frutos, práticas de higienização, processamento para comercialização dos frutos in natura; fabricação de polpas e farinhas, doces, geleias, pães e bolos, embalagem e rotulagem dos produtos, entre outros, conforme Hoehne et al. (2010).

Foram registrados dados dos municípios e dos grupos solidários, associações de

tradicionais da região onde são produzidos (Termo de Referência do Programa Sebrae de Artesanato, 2004). 
produtores rurais e de atividades artesanais, além de cooperativas de extrativismo e produtos com frutos do cerrado. Os registros são atualizados periodicamente, porém apresentam-se somente os dados referentes aos participantes da pesquisa:

- 75 pessoas das comunidades de Cana Brava e São Pedro (Bonfinópolis de Minas) e Serra das Araras (Chapada Gaúcha) - Minas Gerais. Esses indivíduos são agroextrativistas das associações e cooperativas locais, cadastrados pelo Projeto do CETEC e que também participaram das Oficinas de Design para produção artesanal;

- 17 homens membros da Coop Veredas - Cooperativa Regional de Produtores Agrissilviextrativistas Sertão Veredas/ Chapada Gaúcha, MG;

- 14 homens membros da Associação de Produtores Rurais de Bonfinópolis de Minas, incluindo 4 participantes do sindicado de produtores rurais;

- 31 mulheres de ambas as cidades já realizavam alguma atividade artesanal com aproveitamento de materiais locais;

- 12 dessas artesãs são filiadas a grupos solidários ou a associações de artesanato nas comunidades, sendo estas: Associação de moradores e artesãos (Bonfinópolis de Minas) e Associação das Bordadeiras e Artesãos de Serra das Araras (Chapada Gaúcha);

As oficinas de Design, cultura e identidade foram desenvolvidas para propor o aproveitamento de insumos e resíduos vegetais locais. Essas oficinas propiciaram a experimentação dos materiais pelos produtores rurais de Cana Brava, São Pedro, em Bonfinópolis de Minas e de Serra das Araras, em Chapada Gaúcha, no período de 2008 a 2011. Os materiais coletados após os cursos de "Manejo e Beneficiamento com Frutos do Cerrado" e "Produção de Doces e Geleias" possibilitaram a produção de objetos artesanais. Entre os produtos gerados, destacam-se:

Os participantes dos cursos de aproveitamento dos frutos do cerrado tiveram a oportunidade de elaborar com folhas secas e galhos (objetos decorativos como arranjos de flores); com sementes secas (adornos pessoais - colares e brincos); com a palha de buriti e de milhos (bonecas decorativas, esteiras, jogos americanos); etc.
O culto às festas de São Antônio, Folia de Reis e o Encontro dos Povos são eventos populares na região. Motivados pelos eventos, que atraem turistas à região, os participantes dos cursos dedicaram-se à produção artesanal. Assim, os produtores rurais e artesãos tiveram oportunidade de experimentar a comercialização dos produtos e conciliar produção artesanal com as atividades extrativistas.

Darci Ribeiro (1995), conhecedor da alma sertaneja, relata em sua obra "O povo Brasileiro - a formação e o sentido do Brasil", o perfil do sertanejo, que ainda hoje reside nos sertões dos cerrados:

O sertanejo arcaico caracteriza-se por sua religiosidade singela tendente ao messianismo fanático, por seu carrancismo de hábitos, por seu laconismo e rusticidade, por sua predisposição ao sacrifício e à violência. E, ainda, pelas qualidades morais características das formações pastoris do mundo inteiro como o culto da honra pessoal, o brio e a fidelidade e suas chefaturas. (RIBEIRO, 1995).

As orientações foram administradas aos artesãos através de palestras sobre design, a comercialização de produtos o reconhecimento do território (identidade, cultura, meio ambiente, tradições entre outros valores locais). A compreensão dos conteúdos ocorre em atividades práticas diversificadas (montagem do mapa local, visitas turísticas ao entorno da comunidade, exercícios didáticos, leituras de poemas, música, debates, etc.).

As mulheres, produtoras rurais e os artesãos, das comunidades de Cana Brava e São Pedro de Bonfinópolis de Minas, recebem os materiais de outros grupos que executam a atividade extrativismo de materiais para o artesanato. Após a produção artesanal, os demais percursos para comercialização são executados pelo grupo solidários e associações locais. Como nesse caso, a estrutura da Economia Solidária visa ao modelo contrário da atual sociedade, que designa ao presidente e, em cadeia direta, a outros representantes o direito de usar o poder. A principal diferença está no repasse completo da representação, aniquilando a manifestação da sociedade.

O grupo de cooperados e outros membros do município de Chapada Gaúcha, em Minas Gerais, participaram do Curso de Beneficiamento de Frutos do Cerrado, 
executado em parceria do CETEC e a "Coop - Sertão Veredas", em janeiro de 2010. Esse curso aprimorou os conhecimentos da comunidade e buscou promover a qualidade dos produtos produzidos pela cooperativa local.

Para os produtores rurais participarem de cursos como este, é necessário apoio entre eles, do poder público local e das associações e cooperativas beneficiadas. O conhecimento e a participação do grupo fortalecem as relações internas. A Economia Solidária evita utilizar a competição no ensino, o saber é compartilhado e as famílias se ajudam mutuamente, no transporte, na alimentação ou na manutenção de suas propriedades.

\section{Resultados}

A Economia Solidária possui princípios básicos de solidariedade, autogestão e relações democráticas, viabilidade socioeconômica e cooperação, que devem ser privilegiados. $\mathrm{O}$ design identifica as possibilidades de atender aos objetivos do modelo socioeconômico, buscando as bases no mapeamento estrutural da instituição, seja ela de grande ou de pequeno porte.

Alguns fatores são relevantes, como a identidade do produto, o território de atuação, a visualização funcional, as parcerias e os desafios. Encontrar um elemento inovador, em sintonia com as possibilidades do produtor, é o desafio. Dos exemplos investigados, destacam alguns elementos, como:

- Buscar capacitação para os produtores: A Coop Sertão Veredas e as associações de moradores e artesãos de Bonfinópolis de Minas apostam na capacitação dos produtores, investindo não só em conteúdos para aprimorar a produção de doces e geleias, mas também, no aproveitamento dos resíduos dos insumos para fomentar o artesanato.

- Investir em novas técnicas e materiais: O grupo de bordadeiras e artesãos de Serra das Araras, depois de alguns anos desenvolvendo uma técnica que fosse compatível aos modelos idealizados, produziu modelos de produtos adequados ao consumidor.

Para cada grupo, associação, cooperativa ou quaisquer outras formas de coorporações que utilizam dos princípios estabelecidos pela Economia Solidária, encontraremos elementos inovadores.

Em novas experiências, os grupos solidários da agricultura familiar, as associações comunitárias e as cooperativas de trabalho, projetam-se no ambiente familiar, visando a recursos para a educação e aos diretos sociais. Têm como perspectiva a construção de um ambiente ético, socialmente justo e sustentável, excluindo o assistencialismo. Através das diversidades, atuando de formas diferenciadas, essa resistência também se manifesta na forma de iniciativa associativa e solidária. Além disso, desperta alternativa estrutural de organização, resgatando valores como ética, justiça e solidariedade, e não mais no lucro e acúmulo indiscriminado.

\section{Conclusão}

Conforme análises, a Economia Solidária representa um modelo de relações econômicas com princípios estabelecidos, adaptáveis a qualquer instituição, sociedade ou grupo de trabalho. Os resultados econômicos nem sempre apresentam efeitos em curto prazo, pois as bases devem se ajustar primeiramente.

Entender a importância do trabalho coletivo, participativo e comunitário, fortalece as relações humanas, sendo esta uma prática atual da sociedade ruralista brasileira. Registra-se a observação de que os consumidores do artesanato de pequenas comunidades devem valorizar, além das qualidades do produto, as raízes culturais e os benefícios da Economia Solidária. Incentivos governamentais se fazem necessários, não obstante a responsabilidade de valorizar a cultura, da identidade e do território, por toda sociedade, proporcionar respeito e condições dignas de sobrevivência, baseadas em experiências enriquecedoras de coletividade e cooperação.

Design e Inovação Social potencializam os impactos no encontro desses conceitos, tratando-se principalmente das possibilidades para a realidade brasileira. O Design contemporâneo é o eixo fundamental para o desenvolvimento de novos produtos e sistemas de serviços, considerando-o como base elementar nas estruturas de inovação.

Definem-se dois ângulos que apontam para o senso comum sobre a amplitude do 
Design: o poder de impacto visual e as diversidades de utilidade. O desenvolvimento de produtos é a ignição da gestão da inovação, configurando-se como ponto de partida da criação para o conhecimento, formando laços com a Economia Solidária.

É importante relatar que, nessas atividades participativas, os ganhos são para todos os envolvidos. Para a equipe da pesquisa, a proposta serviu como mais uma motivação acadêmica, recordando do ditado popular: "mais importante do que dar o peixe, é ensinar a pescar".

Uma associação ou cooperativa consegue se estabelecer em médio ou longo prazo, com efeitos econômicos que podem ser medidos ou quantificados. Trata-se de uma ideologia que vem ganhando espaço em todo o mundo e que busca resgatar o papel social das ciências econômicas.

Contudo ainda há muito que se pesquisar e aplicar em relações sociais justas, viáveis e sustentáveis. Busca-se resgatar valores morais e estabelecer limites entre a produção e consumo, com foco no ser humano, em projetos do design social. Prioriza-se a qualidade de vida, os recursos naturais e o ser humano, no trabalho solidário. Um bom negócio ou produto poderá permanecer com as mesmas características de produção, porém, entrelaçados com a Economia Solidária, contemplará novos meios para alcançar resultados sociais, econômicos, culturais e ambientais.

\section{Referências}

BARBOSA, A. S. Cerrado - biodiversidade e pluralidade. 2008. Disponível em: <http://altairsalesbarbosa.blogspot.com/search? updated- $\min =2008-01$ 01T00\%3A00\%3A00-02\%3A00\&updated-max=200901-01T00\%3A00\%3A00-02\%3A00\&max-results $=21>$. Acesso em: 20 nov. 2013.

BARBOSA, Walmir. Sociologia e trabalho: uma leitura sociológica introdutória. Disponível em: <http:/ / cefetgo. br/goiania/cienciashumanas/images/downloads/monografias/monografias_historia_politica.pdf $>$. Acesso em: 20 nov. 2013.

BISTAGNINO, Luigi. Design sistêmico: uma abordagem interdisciplinar para a inovação. Trad. Lia Krucken. In: Cadernos de estudos avançados em design e sustentabilidade II. MORAES Djion de; KRUCKEN, Lia (Org.). Barbacena, MG: EdUEMG, 2009. p. 13-29.

DAGNINO, Renato Peixoto. Tecnologias sociais: ferramenta para construir outra sociedade. Campinas, SP: Unicamp, 2009.
ENGLER, R. C. Estratégias para inovação sustentável. In: Cadernos de estudos avançados em design e sustentabilidade II. MORAES Djion de; KRUCKEN, Lia (Org.). Barbacena, MG: EdUEMG, 2009. p. 65-78.

ENGLER, Rita (Org.). Design participativo: uma experiência no Vale do Jequitinhonha. Barbacena: EdUEMG, 2010.

FERREIRA, Aurélio. Novo Dicionário Aurélio da Língua Portuguesa. Rio de Janeiro: Nova Fronteira, 1999.

GAIGER, Luis Inácio. Os caminhos da economia solidária no Rio Grande do Sul. In: SINGER, Paul; SOUZA, André Ricardo de (Org.). A economia solidária no Brasil: a autogestão como resposta ao desemprego. São Paulo: Contexto, 2000.

. A Economia Solidária no Brasil e o sentido das novas formas de produção não-capitalistas. Revista $V e$ nezolana de Economia Social, ano 4, n. 8, dez. 2004.

HALL, S. A identidade cultural na pós-modernidade. Trad. Tomaz Tadeu da Silva e Guaracira Lopes Touro. 10. ed. Rio de Janeiro: DP \& A, 2005.

HOBSBAWM, Eric J. Mundos do trabalho. Rio de Janeiro: Paz e Terra, 2000.

HOEHNE, Lidja M. L.; MADEIRA, Fernando A.; MOURÃO, Nadja M. Dimorphandra Sp.: do extrativismo à produção integrada com base fitoecológica. In: SEMINÁRIO DE INICIAÇÃO CIENTÍFICA DA UFOP, 18. Anais... Ouro Preto, MG: UFOP, 2010.

INSTITUTO BRASILEIRO DO MEIO AMBIENTE E DE RECURSOS NATURAIS E RENOVÁVEIS - IBAMA. Reserva Extrativista. Populações Tradicionais. 2003. Disponível em: <hptt/www.ibama.gov.br/resex/pop. htm>. Acesso em: 20 out. 2013.

IBAMA/FUNATURA. Plano de Manejo do Parque Nacional Grande Sertão Veredas. Brasília, julho de 2003.

LIMA, Maria das Graças. A dimensão subjetiva das Relações de Trabalho da Economia Solidária. 2011. Dissertação (Mestrado em Psicologia Social) - Pontifícia Universidade Católica de São Paulo, São Paulo, 2011.

LÜDKE, M.; ANDRÉ, M. Pesquisa em educação: abordagens qualitativas. São Paulo: EPU, 1986.

MANCE, Euclides. A revolução das redes - a colaboração solidária como uma alternativa pós-capitalista à globalização atual. Petrópolis, RJ: Vozes, 1999.

MADEIRA, Fernando A. Projeto de implantação de unidades de beneficiamento e comércio de produtos oriundos da base produtiva local. CETEC/MG - Convênio n. 411/2007. Belo Horizonte: CETEC, 2008.

MADEIRA, Fernando A.; CÈZAR, Eli. Relatório técnico do projeto de implantação de unidades de beneficiamento $e$ comércio de produtos oriundos da base produtiva local em Bonfinópolis de Minas. Belo Horizonte: CETEC-MG, 2009.

MANZINI, Ezio; VEZZOLI, Carlo. O desenvolvimento de produtos sustentáveis: os requisitos ambientais dos produtos industriais. São Paulo: Edusp. Editora da Universidade de São Paulo, 2002.

MOURÃO, Nadja. M. Janeiro doce na Chapada Gaúcha. 2010. Disponível em: <http://www.chapadagaucha.com/ index.php?option=com_content\&view $=$ article\&id=164 
:janeiro-doce-na-chapada-gaucha\&catid $=49$ :destaquesda-pagina-inicial-novas\&Itemid $=27>$. Acesso em: 30 out. 2013.

Sustentabilidade na produção artesanal com resíduos vegetais: uma aplicação prática de design sistêmico no Cerrado Mineiro. 2011. 206f. Dissertação (Mestrado em Design) - PPGD/Universidade do Estado de Minas Gerais, Belo Horizonte, 2011.

NASCIMENTO, Edson. Princípios da Economia Solidária. Brasília, 2006. Disponível em: <www.editoraferreira. com.br/publique/media/edson_toque7.pdf $>$. Acesso em: 10 out. 2013.

PAPANEK, Victor. Design for the Real World. Chicago: Academy Chicago Publishers, 1984. Completely Revised Second Edition.

PENIN, L. Strategic design for sustainable social innovation in emerging contexts: framework and operative strategies. PHD Thesis, Politécnico de Milão. Milão, 2006.

PIANA, Maria Cristina. A construção do perfil do assistente social no cenário educacional [online]. São Paulo: Editora UNESP/Cultura Acadêmica, 2009. 233p. ISBN 978-85-7983-038-9. Available from SciELO Books. Dis- ponívelem: <http://books.scielo.org>. Acesso em: 20 nov. 2013.

RIBEIRO, Darci. O povo brasileiro - a formação e o sentido do Brasil. São Paulo: Companhia das Letras, 1995.

SANTOS, B. S. A crítica da razão indolente: contra o desperdício da experiência. Porto: Edições Afrontamento, 2000.

SEN, Amartya. Desenvolvimento como liberdade. São Paulo: Companhia da Letras, 2000.

SINGER, Paul. Introdução à Economia Solidária. São Paulo: Perseu Abramo, 2002.

SINGER, Paul; SOUZA, Andre. A Economia Solidária no Brasil: a autogestão como resposta ao desemprego. São Paulo: Contexto, 2000.

SOARES, Claudia Lúcia Bisaggio. Moeda Social. In: CATTANI, A. D. et al. (Coord.). Dicionário Internacional da Outra Economia. Coimbra, Portugal: Almedina, 2009.

SOUZA, Alzira Silva de. Cooperativismo de crédito: realidades e perspectivas. Rio de Janeiro: OCERJ, 1992. 